\title{
Association of ITGB3 gene polymorphisms with the risk of developing fetal growth restriction syndrome
}

\begin{abstract}
The article presents a molecular genetic study of the ITGB3 gene polymorphism in pregnant women with fetal growth restriction syndrome.

Purpose: Assessment of the detectability of the association of the ITGB3 gene polymorphism in women with physiological pregnancy and fetal growth restriction syndrome in the uzbek population of the Bukhara region.

Materials and methods: 80 pregnant women were examined during gestation from 8-36 weeks: 40 pregnant women with fetal growth restriction syndrome and 40 women with physiological pregnancy, hospitalized in the department of pathology of pregnant women in the Bukhara city maternity hospital in the city of Bukhara.

Conclusion: The study showed that the functionally unfavorable allele $\mathrm{C}$ and the association of the T / C genotype polymorphism of the ITGB3 gene polymorphism can be a determinant of an increased risk of developing FGRS in Uzbekistan $(\chi 2<0.47 ; \mathrm{P}>0.05)$.
\end{abstract}

Keywords: fetal growth restriction syndrome, endothelial system gene, ITGB3 gene
Volume I0 Issue 4 - 202I

\author{
Aslonova MJ,' Ikhtiyarova GA,' Mavlyanova \\ $\mathrm{NN}^{2}$ \\ 'Bukhara State Medical Institute, Uzbekistan \\ ${ }^{2}$ Republican Specialized Scientific and Practical Medical Center \\ for Obstetrics and Gynecology of the Ministry of Health of the \\ Republic of Uzbekistan, Uzbekistan
}

\begin{abstract}
Correspondence: Makhlie Zh Aslonova,Assistant of the Department of Obstetrics \& Gynecology, Bukhara State Medical Institute; I, Navoi av., Bukhara, 200I I8, Uzbekistan, ORCID 0000-0002-6823-2006, Email dr.makhliyo89@mail.ru
\end{abstract}

Received: July 13, 202I| Published: August 31, 202

\section{Introduction}

Fetal Growth Restriction Syndrome (FGRS) is an urgent problem of obstetric health care practice around the world, which is the cause of perinatal morbidity and mortality, the risk of sudden infant mortality. ${ }^{1}$ According to statistics from the World Health Organization, the number of newborns with fetal growth retardation syndrome in Central Asian countries ranges from $31.1 \%$. In the USA, ROS is observed in $10-15 \%$ of births, while signs of perinatal hypoxia are observed in $30 \%$ of children diagnosed with ROS.

Preserving the health of every child, future citizen of the Republic of Uzbekistan, is a special strategic and highest priority task of the state. Ensuring the health of children is the main task of society. ${ }^{1}$ Demographic problems for Uzbekistan are of great geopolitical and socio-economic importance. The aging processes of society are growing: the proportion of children and adolescents is decreasing, while the shares of middle and elderly age are increasing. ${ }^{2-6}$

FGRS is diagnosed on the basis of a decrease in the body weight of a particular fetus in comparison with the average fetal body weight corresponding to a given gestational age. In foreign publications, three definitions are used: small for gestation age (SGA) - a fetus with a low (below the 10th percentile) weight for a given gestation age, appropriate for gestation age (AGA) - a fetus with a weight corresponding to a given gestation period (between 10 th and 90th percentiles), large for gestation age (LGA) - a fetus with a large (above the 90th percentile) weight for a given gestation period..$^{7-10}$ Reproductive losses and the costs of complex treatment of children with FGRS cause significant social and economic damage (Strizhakov AN Predicting fetal growth retardation syndrome in high-risk pregnant women. ${ }^{9,11-13}$

According to the generally accepted opinion, in the development of FGRS, the main and often initial causes are hemodynamic microcirculatory disorders, as a result of which the trophic function of the placenta is primarily disturbed and only later the gas exchange at the level of the placental barrier changes. The maintenance of fetal activity in case of impaired placental function occurs with the help of compensatory mechanisms acting not only at the tissue level, but also at the cellular and subcellular levels, leading to changes in energy metabolism. ${ }^{8,10,14-16}$

Thus, clinicians are faced with the urgent question of finding new diagnostic criteria that would allow the earliest possible identification of patients with a high risk of developing $\mathrm{ARD}$, diagnosing early manifestations of this pathology to determine obstetric tactics and improve perinatal pathology. ${ }^{15,17-20}$ According to the studies, the development of FGRS is based on a molecular genetic mechanism, which requires more in-depth research in this direction.

The aim of the study was to assess the detectability of the association of the ITGB3 gene polymorphism in women with the physiological course of pregnancy and fetal growth restriction syndrome in the Uzbek population of the Bukhara region.

\section{Materials and research methods}

80 pregnant women were examined during gestation from 8-36 weeks: 40 women with a physiological course of pregnancy and timely delivery, observed from early gestation in antenatal clinics in Bukhara (control group), and 40 pregnant women with FGRS, hospitalized in the department of pathology of pregnant women in the Bukhara city maternity hospital, the city of Bukhara. (main group).

The diagnosis of fetal growth restriction syndrome, classified according to ICD X P00-P96 / P05-P08, was established by the state of body weight below, and body length above the 10th percentile for gestational age. "Light weight" for the calculated period. The examination and treatment of women included in the study was carried out in the department of pathology of pregnant women in the Bukhara city maternity hospital and the Bukhara perinatal center. According to the clinical guidelines of the Ministry of Health of the Republic of Uzbekistan. Inclusion criteria for the study: singleton spontaneous pregnancy, voluntary informed consent of the woman, approval of the local ethics committee. 
Molecular genetic studies were carried out by isolating total genomic DNA from $100 \mu \mathrm{l}$ of whole venous blood by the sorbent method using a set "Proba-GS-Genetics" ("Geno-technology", Uzbekistan). Single-nucleotide polymorphisms (ITGA2) were determined by real-time polymerase chain reaction using an iCycler iQ5 device (Bio-Rad) and "Cardiogenetics. Thrombophilia "("DNA technology", Russia). Genotyping of the C / T polymorphism of the ITGA2 gene was carried out on a real-time PCR amplifier Rotor Gene 6000 Model 65H0-100 (Australia), using a test system from Syntol Cat. No.-NP 555_100_RG (Russia), according to the manufacturer's instructions. Statistical analysis of the results was carried out using the statistical software package "Open Epi 2009, Version 2.3". The frequency of variants of alleles and genotypes (f) was calculated by the formula: $\mathrm{f}=\mathrm{n} / 2 \mathrm{~N}$ and $\mathrm{f}=\mathrm{n} / \mathrm{N}$, where $\mathrm{n}$ is the occurrence of a variant (allele and genotype), $\mathrm{N}$ is the sample size.

\section{Research results}

The age of women in the main group ranged from 17 to 36 years old and averaged $22.5+1.8$ years. The age of the female patients in the control group ranged from 16 to 38 years, averaging $23.2+$ 1.4 years $(p>0.05)$. In terms of pregnancy parity, both groups were comparable. Clinical and functional studies of 80 pregnant women showed that 40 had fetal growth restriction syndrome (FGRS), which was $50 \%$. According to the severity of the ARS, the I severity was diagnosed in $4(10 \%)$, the II degree - in $19(47.5 \%)$ and the III severity - in $13(32.5 \%)$.

Compared to the control group, the patients of the main group had a burdened somatic and obstetric-gynecological history. Among extragenital diseases, cardiovascular disease prevailed in $14(34.2 \%)$ cases of the main group and in $11(28.8 \%)$ cases of the control group. Diseases of the gastrointestinal tract - in 11 (28.5) and 14 (34.3) patients, respectively. Neuroendocrine disorders occurred in 15 (37.1) and 14 (34.3) pregnant women, respectively, in the main and control groups (Figure 1).

When studying the structure of gynecological morbidity, there was a significant increase in the main group of chronic endometritis $8(18.0 \%)$, chronic salpingo-oophoritis $9(22.0 \%)$, benign ovarian neoplasms $5(12 \%)$, infertility $6(16 \%)$ and cervicitis $21(54 \%)$ $(p<0.05)$. Since most of the patients included in the study were multiparous, we analyzed the obstetric history. In the main group, spontaneous miscarriages $8(18.0 \%)$ and intrapartum fetal death 3 $(6.0 \%)(p<0.05)$ were significantly more frequent. Also, $12(30.0 \%)$ patients of the main group had a history of non-developing pregnancy, although there were no significant differences.

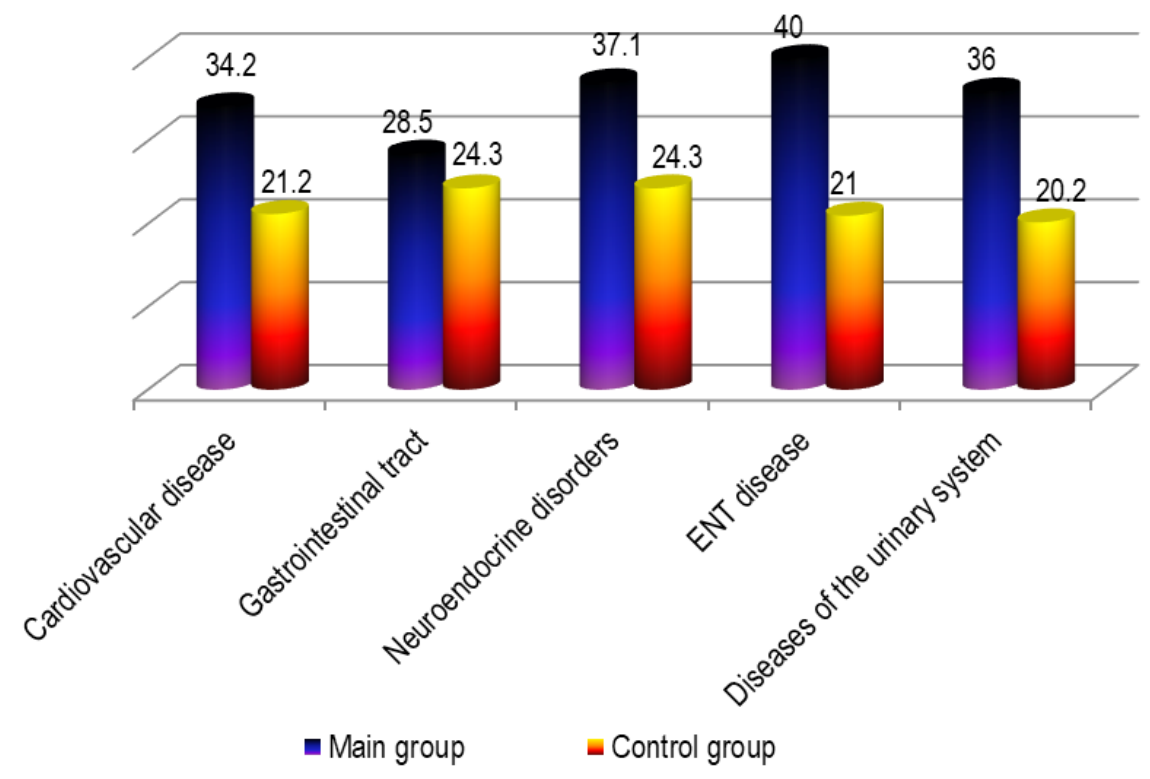

Figure I Somatic and obstetric-gynecological history.

During this pregnancy, among the complications of pregnancy in women, the threat of termination of pregnancy in the first and second trimesters was more often detected $(53.6 \%, \mathrm{p}=0.026)$; gestational arterial hypertension $(12.2 \% \mathrm{p}=0.010)$; development of placental disorders $(100.0 \%, p=0.000)$ (Figure 2$)$. According to the literature, the threat of termination of pregnancy contributes to the defective physiological transformation of the walls of the spiral arteries in the first trimester, impaired blood supply to the placenta, the formation of placental insufficiency and IGR in the second trimester of pregnancy. According to domestic and foreign literature, in any hypertensive disorder, miscarriage, placental insufficiency, RRP, PONRP are often observed. Molecular genetic study of the $\mathrm{C} / \mathrm{T}$ polymorphism of the ITGA2- $\alpha 2$ gene in pregnant women revealed the following indicators (Table 1).
As follows from Table 1, the distribution of alleles of the $T /$ C polymorphism of the ITGB3 gene in pregnant women with a physiological course revealed the presence of a favorable $\mathrm{T}$ allele in $85 \%$ of cases $(68 / 80)$, while the unfavorable $\mathrm{C}$ allele - in $15 \%$ (12), which had a significant character. And in the group of pregnant women with FGRS, the frequency of detection of the favorable allele $\mathrm{T}$ was also $85 \%$ of cases $(68 / 80)$, and the mutant allele $\mathrm{C}-15 \%$ (12), respectively. Analysis of the detectability of the association of polymorphism of genotypes of the ITGB3- gene in the control group of pregnant women showed that the association of polymorphism of favorable T / T genotypes was $72.5 \%$ of cases (29/40), heterozygous genotypes T / C - in $25 \%$ of cases (10/40). Whereas the homozygous variant of the unfavorable genotypes of the ITGB3 gene was $2.5 \%$ $(1 / 40)$, respectively. 


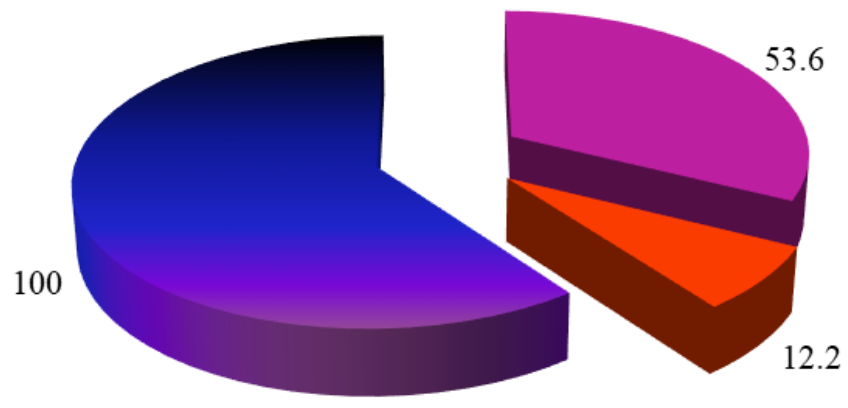

threat of termination of
pregnancy

qestational hypertension

placental insufficiency

Figure 2 Complication of pregnancy in women with FGRS.

Table I Frequency of distribution of genotypes of I565 T> C polymorphism of the Gp-IIla (GPIlb / IIla) ITGB3 gene in the groups of pregnant women with and without FGRS

\begin{tabular}{|c|c|c|c|c|c|c|c|c|c|c|c|}
\hline & & \multicolumn{4}{|c|}{ Allele frequency } & \multicolumn{6}{|c|}{ Frequency distribution of genotypes } \\
\hline \multicolumn{2}{|c|}{ Groups } & \multicolumn{2}{|l|}{$\mathrm{T}$} & \multicolumn{2}{|l|}{$\mathrm{C}$} & \multicolumn{2}{|c|}{$\mathrm{T} / \mathrm{T}$} & \multicolumn{2}{|c|}{$\mathrm{T} / \mathrm{C}$} & \multicolumn{2}{|c|}{$\mathrm{C} / \mathrm{C}$} \\
\hline & & $\mathbf{n}^{*}$ & $\%$ & $\mathbf{n}^{*}$ & $\%$ & $\mathbf{n}$ & $\%$ & $\mathbf{n}$ & $\%$ & $\mathbf{n}$ & $\%$ \\
\hline I & Control group Pregnant women without FGRS n=40 (80) & 68 & 85 & 12 & 15 & 29 & 72,5 & 10 & 25 & 1 & 2,5 \\
\hline 2 & Pregnant women with FGRS n=40 (80) & 68 & 85 & 12 & 15 & 30 & 75 & 8 & 20 & 2 & 5 \\
\hline
\end{tabular}

Note: $\mathrm{n}$ is the number of examined patients;

In the group of pregnant women with FGRS, the detection of the association of polymorphism of favorable $\mathrm{T} / \mathrm{T}$ genotypes was $75 \%$ (30/40), and heterozygous variants of $\mathrm{T} / \mathrm{C}$ genotypes $-20 \%$ $(8 / 40)$, respectively. Whereas a homozygous unfavorable variant of $\mathrm{C} / \mathrm{C}$ genotypes was detected in $5 \%$ of cases $(2 / 40)$, respectively. The data obtained indicated that the unfavorable homozygous $\mathrm{C} / \mathrm{C}$ variant of the ITGB3 gene was 2 times higher than that of the control group. Analysis of the obtained molecular genetic results of the study shows that the association of the T / C polymorphism of the ITGB3 gene with the risk of developing fetal growth restriction syndrome is unreliable. $(\chi 2=0.2 ; \mathrm{P}=0.7 ;)$ That is, according to preliminary data, the functionally unfavorable allele $\mathrm{T}$ of the $\mathrm{T} / \mathrm{C}$ polymorphism of the ITGB3 gene is not a significant determinant of an increased risk of developing fetal growth restriction syndrome in the population of the Bukhara region. $(\chi 2<0.47 ; \mathrm{P}>0.05)$. At the same time, there is a weak tendency to an increase in the frequency of the $\mathrm{T} / \mathrm{C}$ genotype of the ITGB3 gene polymorphism in the group of pregnant women with FGRS compared to the group of pregnant women without SORP.

According to Table 2, no significant differences were found between the expected and observed frequencies of the genotypes of the T / C polymorphism of the ITGB3 gene. The observed genotype frequencies correspond to the theoretically expected ones and are in the Hardy-Weinberg equilibrium. According to Table 3, it is noted that there is a weak tendency to an increase in the frequency of the heterozygous T / C genotype of the ITGB3 gene polymorphism in the group of pregnant women with SORP compared to the group of pregnant women without FGRS. According to the calculated OR, the risk of formation in carriers of an unfavorable $\mathrm{T} / \mathrm{C}$ genotype is 1.3 times higher than in non-carriers of this genotype, i.e., the differences between these subgroups turned out to be close to the level of statistical significance $(\chi 2=0.5 ; \mathrm{P}=0.17$;). The data obtained is consistent with the data of literature sources. ${ }^{21-25}$
Table 2 Expected and observed frequency of distribution of genotypes by RHV of T / C polymorphism of the ITGB3 gene in groups of pregnant women without FGRS

\begin{tabular}{|c|c|c|c|c|}
\hline \multirow{2}{*}{ Genotypes } & \multicolumn{2}{|c|}{ Frequency of genotypes } & \multirow{2}{*}{$x^{2}$} & \multirow{2}{*}{$\mathrm{P}$} \\
\hline & Observable & Expected & & \\
\hline $\mathrm{T} / \mathrm{T}$ & 72,5 & 72,25 & 0,0 & \multirow{4}{*}{0,9} \\
\hline$T / C$ & 25,0 & 25,5 & 0,004 & \\
\hline $\mathrm{C} / \mathrm{C}$ & 2,5 & 2,3 & 0,01 & \\
\hline Total & 100,00 & 100,00 & 0,015 & \\
\hline
\end{tabular}

Table 3 Expected and observed frequency of distribution of genotypes by RHV of T / C polymorphism of the ITGB3 gene in groups of pregnant FGRS

\begin{tabular}{lllll}
\hline \multirow{2}{*}{ Genotypes } & \multicolumn{2}{l}{ Frequency of genotypes } & \multirow{2}{*}{$\mathbf{2}^{2}$} & $\mathrm{P}$ \\
\cline { 2 - 3 } & Observable & Expected & & \\
\hline $\mathrm{T} / \mathrm{T}$ & 75,0 & 72,25 & 0,042 & \\
$\mathrm{~T} / \mathrm{C}$ & 20,0 & 25,5 & 0,47 & \\
$\mathrm{C} / \mathrm{C}$ & 5,0 & 2,25 & 1,3 & 0,17 \\
Total & 100,00 & 100,00 & 1,8 & \\
\hline
\end{tabular}

\section{Conclusions}

The association of the T / C polymorphism of the ITGB3 gene tends to increase the risk of developing fetal growth restriction syndrome. $(\chi 2=0.5 ; \mathrm{P}=0.17)$. A preliminary analysis of molecular genetic studies shows that. that the functionally unfavorable allele $\mathrm{C}$ and the association of the $\mathrm{T} / \mathrm{C}$ genotype polymorphism of the ITGB3 gene polymorphism may be a determinant of an increased risk of developing SORP in Uzbekistan $(\chi 2<0.47 ; \mathrm{P}>0.05)$. 


\section{Acknowledgments}

None.

\section{Funding}

None.

\section{Conflicts of interest}

None.

\section{References}

1. Arutyunyan AV, Zainulina MS, Kornyushina EA, et al. Modern approaches to diagnosis, drug therapy and prevention of obstetric complications in women with thrombophilia. Journal of Obstetrics and Women's Diseases. 2010;LIX (4):90-98.

2. Aslonova MZh, Ikhtiyarova GA, Khafizova DB, et al. Microbiological and hormonal characteristics of the formation of non-developing pregnancy // Fundamental and practical issues of immunology and infectious diseases. Collection of scientific articles of the participants of the international scientific-practical conference UFA. 2018;S:9-15.

3. Dustova NK, Ikhtiyarova GA, Aslonova MZh. The role of infectious factors in fetal loss syndrome. Tibbiyotda yangi kun. 2020;1 (30/2):116119.

4. Ikhtiyarova GA, Aslanova MZh, Dustova NK. Microbiological changes in pregnant women with antenatal fetal death // Euaropean journal of research. 2019;2:102-109.

5. Ikhtiyarova GA, Aslonova M Zh, Dustova NK. Early markers of fetal growth restriction syndrome. Reproductive Medicine. 2020;3:S48-S51.

6. Ikhtiyarova GA, Aslanova MZh, Dustova NK. Microbiological changes in pregnant women with antenatal fetal death // Euaropean journal of research. 2019;2:102-109.

7. Dustova NK, Ikhtiyarova GA, Aslonova MZh. Correlation of cytokine status and vascular endothelial growth factor in pregnant women with chronic venous insufficiency. Tibbiyotda yangi kun. 2020;S:197-201.

8. Ikhtiyarova GA, Aslonova MZh, Khafizova DB. Microbiological and hormonal characteristics of the formation of non-developing pregnancy. Fundamental and practical issues of immunology and infectious diseases. 2018;C:9-15.

9. Spiridonova MG, Trifonova EA, Falyushina SV, et al. Molecular genetic analysis of polymorphic markers of genes responsible for the functioning of the factors of the endothelial system in connection with the complicated course of pregnancy. Medical genetics. 2007;6(7):38-42.

10. Mavlyanova NN, Ixtiyarova GI, Tosheva II, et al. The State of the Cytokine Status in Pregnant Women with Fetal Growth Retardation. $J$ Med ClinRes \& Rev. 2020;4(6):1-4.

11. Bakhramova SU, Ikhtiyarova GA, Dustova NK, et al. Thrombophilic Complications in the Development of Gestional Hypertension. Annals of the Romanian Society for Cell Biology. 2021;6198-6205.
12. Hiltunen LM, Laivuori H, Rautanen A, et al. Factor V Leiden as a risk factor for preterm birth - a population-based nested case- control study. $J$ Thromb Haemost. 2011;9(1):71-78.

13. Ikhtiyarova GA, Tosheva II, Aslonova MJ, et al. Prenatal rupture of amnion membranes as A risk of development of obstetrics pathologies. European Journal of Molecular and Clinical Medicine. 2020;7(7):530 535.

14. Mashkova TYa. The clinical significance of determining the factors of angiogenesis, genetic and acquired forms of thrombophilia in the system of measures for the prevention of repeated IVF failures. Dissertation. 2016:28.

15. Druil L, Damante G, D'Elia A, et al. Genetic thrombophilias and uterine artery Doppler velocimetry and preeclampsia. Int $J$ Gynae col Obstet. 2005;88:265-270

16. Takhmina K, Zavkibekova. Differential markers for the diagnosis of recurrent benign ovarian tumors in women of reproductive and premenopausal age. International Journal of Pharmaceutical Research. $2021 ; 13(1)$.

17. Karimov Kh Ya, Saidov AB, Boboev KT, et al. Fundamental and applied aspects of molecular genetics in medicine. Scientific publication. Tashkent: IPTD “Uzbekistan”. 2016:352.

18. Mozgovaya EV. Study of genetic predisposition to preeclampsia: polymorphism of genes involved in the regulation of endothelial function / E.V. Brain. Journal of Obstetrics and Women's Diseases. 2003;2:25-34.

19. Shakhnoza F Bakhodirova, Gulchekhra A Ikhtiyarova, Aslonova MJ, et al. Davlatov. Features of perinatal outcomes in women after supporting reproductive technologies. European Journal of Molecular \& Clinical Medicine. 2020;7(2): 6350-6356.

20. Tosheva II, Ikhtiyarova GA, Aslanova MJ. Introduction of childbirth in women with the discharge of amniotic fluid with intrauterine fetal death. Journal of Problems and solutions of advanced scientific research. 2019:417-419.

21. Tretyakova TB, Bashmakova NV, Demchenko NS. Genetic predictors of obstetric complications: intergenic associations. Russian Bulletin of Obstetrician-Gynecologist. 2012;6:18-20.

22. Khruslov MV, Boeva MI, Zhabin SN, et al. The incidence of thrombophilic polymorphisms in women with fetal loss syndrome living in the Kursk region. Thrombosis, hemostasis and rheology. 2014;3:35-38.

23. Faisel F, Romppanen EL, Hiltunen M, et al. Susceptibility to pre-eclampsia in Finnish women is associated with $\mathrm{R} 485 \mathrm{~K}$ polymorphism in the factor $\mathrm{V}$ gene, not with Leiden mutation. Eur J Hum Genet. 2004;12(3):187-191.

24. Gargano JW, Holzman CB, Senagore PK, et al. Polymorphisms in thrombophilia and renin-angiotensin system pathways, preterm delivery, and evidence of placental hemorrhage. Am J Obstet Gynecol. 2009;201(3):317.e1-317.e9.

25. Ikhtiyarova GA, Dustova NK, Kudratova RR, et al. Pre-Course Training of Women With Reproductive Loss of Fetus in Anamnesis. Annals of the Romanian Society for Cell Biology. 2021:6219-6226. 